\title{
Sequential fed-batch fermentation of 1,3-propanediol from glycerol by Clostridium butyricum DL07
}

\author{
Xiao-Li Wang ${ }^{1}$, Jin-Jie Zhou ${ }^{1}$, Jun-Tao Shen ${ }^{1}$, Ya-Feng Zheng ${ }^{1}$, yaqin sun $^{1}$, and Zhi-Long \\ $\mathrm{Xiu}^{1}$ \\ ${ }^{1}$ Dalian University of Technology
}

May 8, 2020

\begin{abstract}
The demand for 1,3-propanediol (1,3-PDO) has increased sharply due to its role as a monomer for the synthesis of polytrimethylene terephthalate (PTT). Although Clostridium butyricum is considered to be one of the most promising bio-producers for 1,3-PDO, its low productivity hinders its application on industrial scale because of the longer time needed for anaerobic cultivation. In this study, an excellent mutant of C. butyricum (DL07) was obtained with high-level titer and productivity of 1,3-PDO, i.e. $104.78 \mathrm{~g} / \mathrm{L}$ and $3.38 \mathrm{~g} /\left(\mathrm{L}^{*} \mathrm{~h}\right)$ vs. $94.23 \mathrm{~g} / \mathrm{L}$ and $3.04 \mathrm{~g} /\left(\mathrm{L}^{*} \mathrm{~h}\right)$ using pure or crude glycerol as substrate in fed-batch fermentation, respectively. Furthermore, a novel sequential fed-batch fermentation was investigated, in which the next bioreactor was inoculated by C. butyricum DL07 cells growing at exponential phase in the prior bioreactor. It could run steadily for at least eight cycles. The average concentration of 1,3-PDO in eight cycles was $84.62 \mathrm{~g} / \mathrm{L}$ with the average productivity of $3.05 \mathrm{~g} /(\mathrm{L} * \mathrm{~h})$. The sequential fed-batch fermentation could achieve semi-continuous production of 1,3-PDO with higher productivity than repeated fed-batch fermentation, and would greatly contribute to the industrial production of 1,3-propanediol by $C$. butyricum. Key words: 1,3-Propanediol; glycerol; Clostridium butyricum; sequential fed-batch fermentation
\end{abstract}

\section{INTRODUCTION}

1,3-Propanediol is a versatile chemical compound with wide application in plastics, lubricants, cosmetics, pharmaceuticals and other fields. Especially, it is a crucial monomer for the synthesis of a novel biodegradable polymer, polytrimethylene terephthalate (PTT). PTT has been used in the textile industry for making carpets, apparel and fibre owing to its superior properties such as easy dye-ability, good resilience and softness(Kaur, Srivastava, \& Chand,2012;Lee et al.,2015;Liu, Xu, Zheng, \& Liu,2010). The demand of 1,3PDO is growing rapidly with the profitable textile industry. At present, the production of 1,3-PDO can follow chemical and biological routes. Considering the mild reaction conditions and sustainable development of bioproduction, the bioconversion of 1,3-PDO has attracted great interest from researchers (Jiang, Wang, Wang, \& Fang,2016;Saxena, Anand, Saran, \& Isar,2009;Sun et al.,2018;Vivek, Pandey, \& Binod,2017;Xiu \& Zeng,2008).

Currently, glycerol, an alternative feedstock, is the most common substrate to produce 1,3-PDO for most 1,3-PDO-producing strains(Parate, Mane, Dharne, \& Rode,2018). Interestingly, glycerol is an inevitable by-product of biodiesel, oleochemical industry, soap manufacturing and bioethanol production (Anitha, Kamarudin, \& Kofli,2016;Rahim et al.,2020;Ringel, Wilkens, Hortig, Willke, \& Vorlop,2012). Hopefully, for the valorization of glycerol, the surplus of waste glycerol could be reduced by the bioproduction of high valueadded 1,3-PDO(Westbrook et al.,2019;Yang, Hanna, \& Sun,2012). In nature, some specific microorganisms, including Clostridium, Klebsiella ,Citrobacter, and Enterobacter (Chatzifragkou \& Papanikolaou,2012), can consume glycerol to produce 1,3-PDO. Among them,K. pneumoniae and C. butyricum are the most 
prominent 1,3-PDO producers considering their performance in high productivity and concentration of 1,3PDO(Chatzifragkou \& Papanikolaou,2012;Saxena et al.,2009). C. butyricum is thought to be the most potential strain to produce 1,3-PDO on an industrial scale because it is probiotics, anaerobic culture and vitamin $\mathrm{B}_{12}$-independent(Cassir, Benamar, \& La Scola,2016;Ringel et al.,2012; Yang et al.,2019). Thus many efforts have been made to accelerate the industrial production of 1,3-PDO by C. butyricum .

Many fermentation processes, such as batch, fed-batch, continuous, repeated batch and repeated fed-batch fermentation, were tried to produce 1,3-PDO(Guo et al.,2017;Oh, Lee, Heo, Seo, \& Kim,2018a;Tee, Jahim, Tan, \& Kim,2017; Yang et al.,2017;Zhou et al.,2017;Zhou, Shen, Wang, Sun, \& Xiu,2018). Normally, fed-batch fermentation is recommended to be suitable for the industrial production due to its higher concentration of 1,3-PDO in all fermentation processes(Yang et al.,2018;Zhou et al.,2017). Further, repeated fed-batch fermentation was proposed to overcome some challenges in fed-batch fermentation, such as low overall productivity of 1,3-PDO and long time for seed culture (Oh, Lee, Heo, Seo, \& Kim,2018b;Xue, Li, Li, Xia, $\&$ Ye,2010). Repeated fed-batch fermentation is to pump out most of fermentation broths and remain an amount at the end of fed-batch fermentation, followed by fresh medium. To some extents, repeated fedbatch fermentation avoids the seed culture time between two fed-batches and enhances the overall products productivity, which is great promising for industrial 1,3-PDO production(Oh et al.,2018a). Considering the sustainable operations and overall productivity in industry, however, there are also some specific barriers and potential problems to repeated fed-batch fermentation. For example, the repeated fed-batch fermentations were investigated by $K$. pneumoniae only, which is pathogenic and vitamin $\mathrm{B}_{12}$-dependent. Additionally, low 1,3-PDO concentration (66 g/L) (Xue et al.,2010) and more by-products were obtained (37.5 g/L 2.3propanediol) (Oh et al.,2018a). More importantly, the number of cycles is worrying, as the seed broths of each cycle come from the last cycle of fermentation, in which the microbial cells are at the decline phase. Undoubtedly, increasing the number of cycles and shortening the interval between the two cycles of inoculation will greatly reduce the infection risk of industrial production and further improve the overall 1,3-PDO productivity. Besides, reducing the production cost of the 1,3-PDO will make the factory profitable. The costs of carbon, organic nitrogen source and aerating nitrogen are the main obstacles to industrial production of 1,3-PDO(Ju et al.,2020;Wischral et al.,2016).

In this study, the production of 1,3-PDO by $C$. butyricum DL07 was evaluated in fed-batch fermentation using crude or refined glycerol as a substrate. Moreover, a sequential fed-batch fermentation process, whose seed broths was derived from the microbial exponential-phase of the last cycle fermentation, was proposed firstly to achieve semi-continuous and stable 1,3-PDO production by $C$. butyricum . It offers several advantages over previous fermentation processes, such as maintaining inoculum in good growth state, avoiding the individual culture of inoculation, shortening 1,3-PDO harvestable interval during every two cycles, and obtaining higher overall productivity. Certainly, an increase in number of cycles is expected to retain still stable 1,3-PDO concentration. Therefore, it is of great significant for industrial production to explore the production of 1,3-PDO in sequential fed-batch fermentation by C. butyricum. After that, the effects of corn steep liquor power and different aerating gases $\left(\mathrm{N}_{2}, \mathrm{H}_{2}, \mathrm{CO}_{2}\right.$, and fermentation exit gas) on the production of 1,3-PDO were studied so as to reduce the fermentation cost. Based on the optimization of fermentation conditions, it contributes to the 1,3-PDO production by microbial fermentation in industry. At the same time, this new fermentation process will facilitate further on a pilot and industrial scale.

\section{MATERIALS AND METHODS}

\section{Material}

Crude glycerol was provided by Sichuan Tianyu Oleochemical Co. Ltd., China. Its components include $78 \%$ glycerol, $0.87 \%$ ash, $15-17 \%$ moisture, and a little salt (the equivalent of electrical conductivity as $0.43 \%$ sodium chloride), and the $\mathrm{pH}$ value was 6.91 (Zhou et al.,2017). Active sludge was collected from an anaerobic digester at Dongtai Industrial Waste Treatment Co., Ltd., Dalian, China. The strain, $C$. butyricum DL07, was selected from the active sludge using seed medium and had been deposited in China General Microbiological Culture Collection Center (CGMCC, Beijing, China) and the accession number is CGMCC 17934. Bioreactors equipped with an automatic pH control system were requisite. 


\section{Culture media}

The compositions of seed medium were similar to those described by Zhou et al.(Zhou et al.,2017). The solid seed medium for the selection of C. butyricum DL07 had the same chemicals as seed medium with addition of $1.2 \%$ agar. Fermentation medium for 1,3-PDO production was accordance with Jiang et al.(Jiang, Liu, $\mathrm{Mu}$, Sun, \& Xiu,2017), except that glycerol in the fermentation medium will be confirmed as either crude or refined glycerol according to the experimental needs. Moreover, the yeast extract in fermentation medium was replaced with corn steep liquor powder on the basis of experimental design. The feeding solution for 1,3-PDO production was glycerol or $80 \%$ glycerol with $40 \mathrm{~g} / \mathrm{L}$ yeast extract.

\section{Culture conditions}

$4 \%$ (v/v) of strain stored at $-70^{\circ} \mathrm{C}$ was inoculated into $250 \mathrm{~mL}$ anaerobic serum bottles containing $100 \mathrm{~mL}$ of seed medium sterilized at $121^{\circ} \mathrm{C}$ for $15 \mathrm{~min}$ and aerated by nitrogen. The seed culture was incubated at $37^{\circ} \mathrm{C}$ and $200 \mathrm{rpm}$ for 12 hours. Fermentations were carried out in a 5.0 L bioreactor (Baoxing Biotech, Shanghai, China) with $2.0 \mathrm{~L}$ sterilized fermentation medium. $10 \%(\mathrm{v} / \mathrm{v})$ of the seed culture broths was inoculated into the first bioreactor. $\mathrm{N}_{2}$ was aerated into bioreactor to create an anaerobic environment. The bioreactor ran automatically at $37^{\circ} \mathrm{C}, 250 \mathrm{r} / \mathrm{min}$, and $\mathrm{pH} 7.0$ controlled by $5 \mathrm{~mol} / \mathrm{L} \mathrm{NaOH}$ solution throughout the fermentation process.

\section{Selection and storage of strain}

$1 \mathrm{~mL}$ of anaerobic active sludge was mixed with $9 \mathrm{~mL}$ of sterile deoxidized water in serum bottle using a sterile syringe. The mixture was placed in a water bath at $80^{\circ} \mathrm{C}$ for $10 \mathrm{~min}$ to kill non-spore forming bacteria. The $100 \mu \mathrm{L}$ mixture was laid on the solid seed medium and cultured at $37^{\circ} \mathrm{C}$ in anaerobic incubator. After $12 \mathrm{~h}$ of culture, the largest colony of bacteria continued to be cultivated to purify the single bacteria. Based on serial purification, the single colony DL07 was finally isolated. Then the strain DL07 was enriched with liquid seed medium and cultured repeatedly using fermentation medium so as to improve its performance for 1,3-PDO production. The strain DL07 was identified as C. butyricumsubsequently. Finally, C. butyricum DL07 was stored at $-70^{\circ} \mathrm{C}$ in a seed medium with $40 \%$ glycerol.

\section{Fed-batch fermentation of 1,3-PDO}

Fed-batch fermentations were performed by means of two strategies: continuous and pulsed feeding. In continuous fed-batch fermentation, residual glycerol concentration was controlled at about $20 \mathrm{~g} / \mathrm{L}$ during the fermentation by manually adding the feeding solution. In pulsed fed-batch fermentation, glycerol was added into bioreactor to reach the preset value for three times, when the residual concentration of glycerol was below $20 \mathrm{~g} / \mathrm{L}$.

The sequential fed-batch fermentation process was shown in Figure 1, in which the next bioreactor was inoculated by $C$. butyricum DL07 cells growing at exponential phase in the prior bioreactor. Firstly, the seed culture was scaled up three times. Then $2 \%$ of seed broth was added into the first bioreactor. When the first bioreactor ran to $10 \mathrm{~h}, 40 \mathrm{~mL}$ fermentation broth ( $2 \%$ inoculation) was inoculated to the second bioreactor to start the second cycle of fermentation. Meanwhile, the first bioreactor proceeded as a fed-batch fermentation. The following fermentations were carried out in the same way. In order to study aerating gas fermentation, the exit gas produced in the first bioreactor was aerated directly into the second bioreactor before inoculation to create an anaerobic environment.

\section{Analytical methods}

The cell mass was monitored by measuring the optical density of the cultured broths at $650 \mathrm{~nm}$ with appropriate dilution using a UV-visible spectroscopy system. Glycerol was determined by adding specific $\mathrm{NaOH}$ solution into a reaction solution where glycerol reacted with excess sodium periodate and then unreacted sodium periodate was reacted with ethylene glycol (Wang et al. 2001). The concentration of glycerol, 1,3PDO, butyrate, acetate, lactate, and formate were determined by HPLC analysis system (Waters 1515) using an Aminex HPX 87H column (300 mm × $7.8 \mathrm{~mm}$; Bio-Rad) coupled with an autosampler (Waters 2707) 
and a differential refractometer ( Waters 2414). Operating conditions: sample volume $20 \mu \mathrm{L}$, mobile phase $5 \mathrm{mmol} / \mathrm{L} \mathrm{H}_{2} \mathrm{SO}_{4}$, flow rate $0.6 \mathrm{~mL} / \mathrm{min}$, detector temperatures $35^{\circ} \mathrm{C}$, column temperature $65^{\circ} \mathrm{C}$. Testing samples, which are obtained from the fermentation broths after centrifuging for 10 minutes at 12,000 r/min, were diluted appropriately and filtered through $0.22-\mu \mathrm{m}$ membranes filter before the test.

\section{Statistical analysis}

Linear regression was accomplished using Microsoft Excel software after collecting a large amount of data point. A significance test was recommended using two-tailed paired Student's t-test, and $\mathrm{p}<0.05$ was considered significant.

\section{RESULTS}

\section{Fed-batch fermentation of a novel strain}

To evaluate the ability of $C$. butyricum DL07 to produce 1,3-PDO, fed-batch fermentation was performed with two feeding strategies. Meanwhile, pure and crude glycerol were investigated as feeding solution respectively. Fed-batch fermentation coupled with continuous feeding was conducted with an initial glycerol concentration of $40 \mathrm{~g} / \mathrm{L}$ and then $20 \mathrm{~g} / \mathrm{L}$ during the fermentation. Nitrogen was pumped into bioreactor at $0.15 \mathrm{vvm}$ for $1 \mathrm{~h}$ before and after inoculation to create an anaerobic environment. As shown in Figure 2, the rate of glycerol consumption and 1,3-PDO production rose rapidly between 3-10 h, so the highest 1,3-PDO productivity $(10.43 \mathrm{~g} /(\mathrm{L}[?] \mathrm{h}))$ occurred in this period. The final 1,3-PDO concentration was up to 85.96 $\mathrm{g} / \mathrm{L}$ with pure glycerol and $85.47 \mathrm{~g} / \mathrm{L}$ with crude glycerol. Respectively, the overall 1,3-PDO productivity

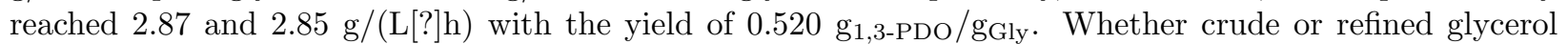
as substrate, the highest OD value, representing the maximum biomass, appeared at $13 \mathrm{~h}$ with OD value of 15.76 and 14.73, respectively. Additionally, butyric acid was the most by-product with concentrations ranging from about 15.11 to $16.65 \mathrm{~g} / \mathrm{L}$. The concentrations of acetic acid, followed by butyric acid, were about 9.22- $9.71 \mathrm{~g} / \mathrm{L}$. When glycerol was pumped by three-pulse strategy, the concentrations of 1,3-PDO and organic acid approached that in continuous fed-batch fermentation. And 84.98 and $84.86 \mathrm{~g} / \mathrm{L} 1,3-\mathrm{PDO}$ were produced using pure and crude glycerol as substrate, respectively. Similarly, the 1,3-PDO productivity

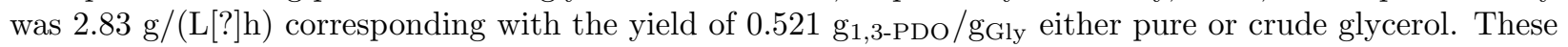
values were also at the same level with those of fed-batch fermentation by continuous feeding. The highest OD value also appeared at $13 \mathrm{~h}$ but decreased slightly compared to continuous fed-batch fermentation.

\section{Effect of organic nitrogen resource on the production of 1,3-PDO}

The costs of nitrogen and carbon source are the key factors in 1,3-PDO production. In fed-batch fermentation, 1,3-PDO concentration by pure glycerol fermentation was similar with that by crude glycerol fermentation. As a result, refined glycerol can be substituted by crude glycerol for 1,3-PDO production so as to reduce the cost of 1,3-PDO production. Furthermore, the addition of yeast extract and core steep liquor powder was investigated. When the feeding solution consisted of $80 \%$ glycerol and $40 \mathrm{~g} / \mathrm{L}$ yeast extract, continuous fed-batch fermentation was performed with $0.1 \mathrm{vvm}$ nitrogen through fermentation. Unexpectedly, the concentration of 1,3-PDO increased significantly whether crude or refined glycerol as substrate. Using pure glycerol and yeast extract as feeding solution, the maximum 1,3-PDO concentration was in surprise up to $104.78 \mathrm{~g} / \mathrm{L}$ (Figure $3 \mathrm{a}$ ) with a productivity of $3.38 \mathrm{~g} /(\mathrm{L}[?] \mathrm{h})$, which was $21.9 \%$ higher than that using only glycerol as the feeding solution. The by-products and biomass also had relative high concentrations. Specifically, $19.63 \mathrm{~g} / \mathrm{L}$ butyrate and $10.52 \mathrm{~g} / \mathrm{L}$ acetate were obtained at the end of fermentation. The 1,3-PDO conversion rate was $0.539 \mathrm{~g}_{1,3-\mathrm{PDO}} / \mathrm{g}_{\mathrm{Gly}}$. However, when using crude glycerol and yeast extract as feeding solution, the concentration of 1,3-PDO and butyrate decreased to 94.23 and $14.87 \mathrm{~g} / \mathrm{L}$ (Figure $3 \mathrm{~b})$ respectively. Acetate concentration $(12.90 \mathrm{~g} / \mathrm{L})$ was higher. The highest $\mathrm{OD}$ value was $23.3 \%$ lower compared with that of pure glycerol fermentation. Lastly, an overall productivity was $3.04 \mathrm{~g} /\left(\mathrm{L}^{*} \mathrm{~h}\right)$ with a

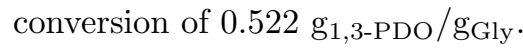

Corn steep liquor powder, an inexpensive nitrogen source, can be used as organic nitrogen instead of yeast extract for 1,3-PDO production on account of vitamin $\mathrm{B}_{12}$-independent in C. butyricum . Fed-batch fermen- 
tations by three-pulse strategy with crude glycerol were conducted using 4 and $6 \mathrm{~g} / \mathrm{L}$ corn steep liquor power as organic nitrogen source. The results were shown in Figure 4. When the concentration of corn steep liquor power was $4 \mathrm{~g} / \mathrm{L}$, respectively, the concentrations of 1,3-PDO, butyrate and acetate were 82.05, 15.03 and $11.32 \mathrm{~g} / \mathrm{L}$ with no obvious difference in contrast to yeast extract as nitrogen source in fermentation. And there was no significant fluctuation in 1,3-PDO productivity and yield with the change of nitrogen sources. Otherwise, microbial growth was slightly slower. When $6 \mathrm{~g} / \mathrm{L}$ corn steep liquor power was added in medium, the concentration of 1,3-PDO went up to $88.25 \mathrm{~g} / \mathrm{L}$ with the increase of biomass. It seems corn steep liquor powder as a perfect nitrogen substitute can significantly reduce the production cost of 1,3-PDO to promote the industrial production of 1,3-PDO.

\section{Effect of aerating gas on the production of 1,3-PDO}

Nitrogen is used extensively in the conversion of glycerol to 1,3-PDO by C. butyricum, since C. butyricum is anaerobic bacteria and undergoes anaerobic fermentation. It is all known that $\mathrm{CO}_{2}$ and $\mathrm{H}_{2}$ are produced by $C$. butyricum during the glycerol fermentation. The produced $\mathrm{CO}_{2}$ is of no value and its emissions to environment can put pressure on environmental protection. Hence, if the gas produced by fermentation could be substituted for nitrogen for the next fermentation, it would avoid the cost of carbon dioxide treatment and reduce the use of nitrogen. Fed-batch fermentations were conducted, in which gas produced by fermentation was used to create an anerobic environment instead of nitrogen. The gas from a traditional fed-batch fermentation before $10 \mathrm{~h}$ passed through the second fermentation. Then the second fermentation started with 10\% inoculation. As shown in Figure 5, the concentration of 1,3-PDO (76.58 g/L) in the second fermentation (fermentation exit gas as an aeration gas) was slightly lower than that $(82.60 \mathrm{~g} / \mathrm{L})$ in the first fermentation $\left(\mathrm{N}_{2}\right.$ as an aeration gas ), but the productivity of 1,3-PDO $(3.38 \mathrm{~g} /(\mathrm{L}[?] \mathrm{h}))$ increased by $23 \%$. Unfortunately, the conversion rate of $1,3-\mathrm{PDO}$ was only $0.481 \mathrm{~g}_{1,3-\mathrm{PDO}} / \mathrm{g}_{\mathrm{Gly}}$, which was lower than that of the first fermentation $\left(0.513 \mathrm{~g}_{1,3-\mathrm{PDO}} / \mathrm{g}_{\mathrm{Gly}}\right)$. On the contrary, the concentration of butyric acid was higher. Then, $\mathrm{H}_{2}$ and $\mathrm{CO}_{2}$ took the place of $\mathrm{N}_{2}$ to explore their effects on fed-batch fermentation, respectively. The results (Figure 5) showed that 1,3-PDO, butyrate and acetate concentrations $(81.34,15.24$ and $10.50 \mathrm{~g} / \mathrm{L}$ ) remained a same level whether hydrogen or nitrogen for creation of anaerobic fermentation environment. Similarly, the productivity and conversion rate of 1,3-PDO ( $2.80 \mathrm{~g} /(\mathrm{L}[?] \mathrm{h})$ and $\left.0.520 \mathrm{~g}_{1,3-\mathrm{PDO} / \mathrm{g} \text { Gly }}\right)$ remained basically unchanged. However, when $\mathrm{CO}_{2}$ was used to create anerobic environment, the concentration of 1,3-PDO $(78.77 \mathrm{~g} / \mathrm{L})$ showed a slight decrease compared to $\mathrm{N}_{2}$ pumped into bioreactor, but was essentially similar with fermentation exit gas as aeration gas. And other by-products concentrations $(15.95 \mathrm{~g} / \mathrm{L}$ butyrate and $8.52 \mathrm{~g} / \mathrm{L}$ acetate $), 1,3-\mathrm{PDO}$ conversion rate $\left(0.477 \mathrm{~g}_{1,3-\mathrm{PDO}} / \mathrm{g}_{\mathrm{Gly}}\right)$ and productivity were consistent with those of fermentation exit gas as aeration gas.

\section{sequential fed-batch fermentation}

The sequential fed-batch fermentation was carried out followed the Figure 1 with three-pulse feeding strategy. To meet the demand of large quantities of seeds in industrial production, seed culture was scaled up three times in three bioreactors. In seed culture process, the inoculation was carried out in sequence, when OD values were 3.020, 3.060 and 5.456 in three bioreactor, respectively, with the corresponding seed culture time of $4,4.5$ and $7 \mathrm{~h}$. As a consequence, $15.5 \mathrm{~h}$ was needed to scale up the seed culture before fermentation. There is no doubt that seed culture takes some time in industrial production, and a lot of money also needs to be invested, which will reduce the benefits.

However, after seed culture, if sequential fed-batch fermentation was initiated, then no further seed culture was required. Four bioreactors were required to produce 1,3-PDO with a seed culture of $10 \mathrm{~h}$ simultaneously by the sequential fed-batch fermentation, as it takes about $30 \mathrm{~h}$ to finish fermentation in a fed-batch fermentation. When the first fermentation ran until $10 \mathrm{~h}$, only $2 \%$ of the fermentation broths was inoculated into a new bioreactor with fresh fermentation medium. Then, the process continued in cycles. As a result, the fermentation ran steadily for at least eight cycles and was stopped by human intervention due to lack of technicians to feed glycerol. The concentrations of 1,3-PDO with corresponding productivities, yields even by-products concentrations from the first to eighth cycles were listed in table 1 . The results showed that the highest concentration of 1,3-PDO $(88.59 \mathrm{~g} / \mathrm{L})$ occurred in the second cycle of fermentation. While the 
lowest 1,3-PDO concentration $(80.65 \mathrm{~g} / \mathrm{L})$ was obtained in the eighth cycle of fermentation. This fluctuation in concentrations of 1,3-PDO is acceptable by factory because more than $80 \mathrm{~g} / \mathrm{L} 1,3-\mathrm{PDO}$ is worthy for industrial production. It can be seen from calculation results that the highest and lowest productivities were 3.83 and $2.74 \mathrm{~g} /(\mathrm{L}[?] \mathrm{h})$ in the fifth and third cycle, respectively. The minimum productivity in sequential fed-batch fermentation remained at a same level with the single fed-batch fermentation. The productivities of the second and fifth fermentation were 3.52 and $3.83 \mathrm{~g} /(\mathrm{L}[?] \mathrm{h})$, respectively, which was much higher than the result of single fed-batch fermentation. Overall, the average concentrations of 1,3-PDO, butyrate and acetate were $84.62,16.76$ and $7.28 \mathrm{~g} / \mathrm{L}$. Beyond that, the average productivity was $3.05 \mathrm{~g} /(\mathrm{L}[?] \mathrm{h})$ with a

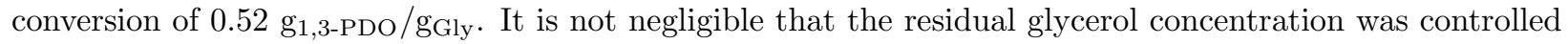
below $10 \mathrm{~g} / \mathrm{L}$ in every fermentation. It's worth noting that the sequential fed-batch fermentation only took $100 \mathrm{~h}$ to finish eight fed-batch fermentations without additional seed culture.

\section{Glycerol feeding strategy based on $\mathrm{NaOH}$ consumption in fed-batch fermentation}

In fed-batch fermentation, glycerol was added into bioreactor manually. Obviously, an automatic feeding system will facilitate the application of 1,3-PDO production in industry. In order to develop glycerol feeding automatically, a large amount of data including the consumption of $5 \mathrm{~mol} / \mathrm{L} \mathrm{NaOH}$ and glycerol, the production of 1,3-PDO, and bacterial growth were collected in sequential fed-batch fermentation to explore their relationships. Fortunately, the specific mass consumption of glycerol showed a good linear relationship with $5 \mathrm{~mol} / \mathrm{L} \mathrm{NaOH}\left(\mathrm{R}^{2}=0.976, \mathrm{p}=0.006\right)$ (Figure 6$) .5 \mathrm{~mol} / \mathrm{L} \mathrm{NaOH}$ was automatically pumped into the bioreactor coupling with a $\mathrm{pH}$ control system, so the mass consumption of $5 \mathrm{~mol} / \mathrm{L} \mathrm{NaOH}$ could be calculated on the basis of the times of delivery recorded in the bioreactor. It was calculated that a total of 198.5-208.5 g/L NaOH solution (5 mol/L) was pumped into the bioreactor to maintain the $\mathrm{pH}(7)$ during a fed-batch fermentation. Based on their linear relationship, the mass of glycerol feeding could be calculated according to the consumption of $5 \mathrm{~mol} / \mathrm{L} \mathrm{NaOH}$. In this way, glycerol feeding could proceed automatically during fermentation.

To practice the feasibility of this linear relationship, fed-batch fermentations were carried out in which glycerol was fed into the bioreactor in terms of the consumption of $5 \mathrm{~mol} / \mathrm{L} \mathrm{NaOH}$ to conform their linear relationship. When the initial glycerol concentration declined from 40 to $20 \mathrm{~g} / \mathrm{L}$, glycerol feeding system was activated in accordance with preset procedure. As predicted, the concentration of glycerol was maintained at about $20 \mathrm{~g} / \mathrm{L}$ with a small fluctuation (Figure 7), which did not interfere with normal fermentation. Because glycerol feeding was ceased at $20 \mathrm{~h}$ of fermentation, the residual glycerol concentration at the end of fermentation was $5.97 \mathrm{~g} / \mathrm{L}$. The concentration of 1,3-PDO was $82.18 \mathrm{~g} / \mathrm{L}$ corresponding with a productivity of $2.74 \mathrm{~g} /(\mathrm{L}[?] \mathrm{h})$. In addition, the butyrate, acetate and cell concentrations were at a same level compared with those of manual feeding, so did the 1,3-PDO yield. In a word, the automatic glycerol feeding system could apply to the production of 1,3-PDO by C. butyricum DL07 fermentation.

\section{DISCUSSION}

\section{High-level production of 1,3-PDO by $C$. butyricum DL07}

Fed-batch fermentation, which is an effective fermentation process to achieve high product concentration, gets extensive attention in microbial fermentation and is feasible for industrial production(Lee et al.,2015). However, the concentration and yield of 1,3-PDO are subject to fluctuation with different feeding methods in fed-batch fermentation(Yang et al.,2018). Thus, two glycerol feeding methods (continuous feeding and three-pulse feeding) were adopted to perform the production of 1,3-PDO by C. butyricum DL07. At the same time, the 1,3-PDO production was assessed with pure and crude glycerol as substrate using two feeding methods, respectively. When feeding solution only contained glycerol in fed-batch fermentation with continuous feeding, there was no difference in the concentrations of 1,3-PDO whether pure glycerol $(85.96 \mathrm{~g} / \mathrm{L} 1,3-\mathrm{PDO})$ or crude glycerol $(85.47 \mathrm{~g} / \mathrm{L})$ as substrate. The same results were validated, although three-pulse feeding was adopted in fed-batch fermentation. In addition, the concentrations of by-products, 1,3-PDO productivity and yield did not appeal to be affected by the quality of glycerol. These suggested that the presence of few impurities in crude glycerol did not affect the production of 1,3-PDO by C. butyricum DL07. Similarly, the concentration of 1,3-PDO and other by-products did not fluctuate significantly with 
the two different feeding methods, whether crude or refined glycerol as substrate. These results indicated that C.butyricum DL07 possess a certain robustness and can produce 1,3-PDO steadily and efficiently under different fermentation conditions. Overall, the concentrations of 1,3-PDO were among 82.76-88.17 g/L with a subtle difference in productivities $(2.74-2.85 \mathrm{~g} /(\mathrm{L}[?] \mathrm{h}))$ in fed-batch fermentation by C.butyricum DL07.

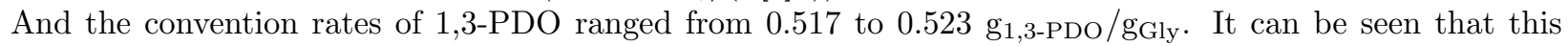
superior C. butyricum is suitable for industrial production of 1,3-PDO because of its excellent production performance.

When the mixture of yeast and glycerol was used as feeding solution, $93.7 \mathrm{~g} / \mathrm{L}$ 1,3-PDO was produced by natural $C$. butyricum in previous report(Wilkens, Ringel, Hortig, Willke, \& Vorlop,2012). In order to motivate the maximum potential of $C$. butyricum DL07 to produce 1,3-PDO, the same feeding solution without concern for cost was used for the production of 1,3-PDO in fed-batch fermentation. Surprisingly, 104.78 and $94.23 \mathrm{~g} / \mathrm{L} 1,3-\mathrm{PDO}$ were obtained with pure and crude glycerol as substrate with an overall productivity of 3.38 and $3.04 \mathrm{~g} /\left(\mathrm{L}^{*} \mathrm{~h}\right)$, respectively. To our knowledge, these are the highest 1,3-PDO concentration for natural producers so far. Some examples for 1,3-PDO production by natural producers are given in Table 2. The maximum tolerance concentration of $C$. butyricum to 1,3-PDO was reported to be 83.7 $\mathrm{g} / \mathrm{L}$ (Colin, Bories, \& Moulin,2000). It can be assumed that the presence of amino acids and vitamins in yeast extract has positive effects on strain for tolerance of the high concentration of 1,3-PDO. It was reported that high-level amino acids in cell were used to response to the deterioration of living environment (Zhang, Liu, Huang, Fu, \& Fang,2018). Moreover, the increased yeast extract in fermentation promoted microbial growth. It has been reported that the addition of amino acids could improve cells growth(Sharma \& Melkania,2018). Obviously, the concentration of 1,3-PDO was relatively lower using crude glycerol, possibly due to the dilution and the accumulation of impurities with the addition of a large amount of crude glycerol to the bioreactor. After all, a microorganism has a certain tolerance for impurities in crude glycerol. It has been reported a certain concentration of salts, fatty acids, heavy metal ions have inhibitory effects on C. butyricum (Chatzifragkou, Dietz, Komaitis, Zeng, \& Papanikolaou,2010;Matsumura, Nomura, \& Sato,2008).

\section{Reduction in 1,3-PDO production cost}

The high production cost of 1,3-PDO is one of the factors hindering its industrial production(Zeng \& Sabra,2011). In order to reduce production costs, the residual glycerol from biodiesel production was used to replace pure glycerol for 1,3-PDO production (Chatzifragkou et al.,2014;Xiu, Wang, Zhou, \& Sun,2019). Besides, soybean cake hydrolysate and corn steep liquor as organic nitrogen in medium were tried to substitute the expensive yeast extract (Maina et al.,2019;Oh et al.,2018a;Wischral et al.,2016). We have concluded that crude glycerol can be used as a substrate for fermentation because of the robustness of $C$. butyricum DL07. Therefore, corn steep liquor powder, as a primary by-product of corn-starch extraction process, was expected to support the growth and fermentation of $C$. butyricum DL07. The results showed that corn steep liquor powder can be used as organic nitrogen source without the loss of 1,3-PDO concentration, yield and productivity. By calculating the cost of production, it is more economical to add $4 \mathrm{~g} / \mathrm{L}$ corn steep liquor powder in fermentation medium. The concentration of corn steep liquor power is relatively lower compared with an addition of $10 \%$ in a report (Oh et al.,2018a) and $30 \mathrm{~g} / \mathrm{L}$ in another report (Wischral et al.,2016).

The fermentation exist gas including more than $95 \% \mathrm{CO}_{2}$ and a little $\mathrm{H}_{2}$ was produced according to the glycerol metabolism pattern of $C$. butyricum for the 1,3-PDO production (Saint-Amans, Girbal, Andrade, Ahrens, \& Soucaille,2001;Zhang et al.,2018). Furthermore, the fermentation exist gas instead of nitrogen creating an anaerobic fermentation environment was performed. Unfortunately, the concentration and conversion rate of 1,3-PDO were lower. In contrast, the productivity of 1,3-PDO and butyric acid concentration were higher. $\mathrm{H}_{2}$ and $\mathrm{CO}_{2}$ were then used to substitute nitrogen for fed-batch fermentation to explore which gas affected the results. It turned out that the existence of $\mathrm{CO}_{2}$, not $\mathrm{H}_{2}$, affected the production of 1,3-PDO. The presence of $\mathrm{CO}_{2}$ reduced the concentration and conversion rate of 1,3-PDO and increased the productivity of $1,3-\mathrm{PDO}$ and butyric acid concentration. This indicated that $\mathrm{CO}_{2}$ causes glycerol metabolism to flow to butyric acid production. It has been reported that $\mathrm{CO}_{2}$ can promote the growth of $C$. butyricum, the growth will be delayed or does not start at all if without $\mathrm{CO}_{2}$ (Hakalehto \& Hänninen,2012). In the future, 
an appropriate mixture of fermentation exist gas and nitrogen used in fermentation is expected to increase productivity without losses of 1,3-PDO concentration and conversion rate. At the same time, there will be a little reduction in the production cost of 1,3-PDO, and the pressure of fermentation exhaust emissions on the environment will also be relieved to a certain extent.

\section{Stable and efficient sequential fed-batch fermentation}

From the perspective of microbial growth (Figure 2 ), the exponential growth period of the strain was between $3 \mathrm{~h}$ and $13 \mathrm{~h}$ in all fed-batch fermentations. As is well known, fermentation will be performed more steadily and successfully, when microbes are used as inoculum at exponential growth period rather than decline phase. In repeated batch and fed-batch fermentations, a majority of fermentation broths were removed, leaving a part of microbes during decline phase as seed in the bioreactor, then a certain fresh fermentation medium was added into the bioreactor (Kaur, Srivastava, \& Chand,2012; Oh et al.,2018a;SzymanowskaPowalowska,2014; Yang et al.,2017). It has been reported that the performance of strain to produce 1,3-PDO decreased as cycle increased (Chatzifragkou et al.,2014;Yang et al.,2017), and even C. butyricum appeared resting body in harsh environments (Zhang et al.,2018). Therefore, the times of cycle is worrying, especially for industrial production although five cycles were carried out successfully with seeds in the decline phase (Oh et al.,2018a). Furthermore, there is no report about repeated fed-batch fermentation by C. butyricum. It is necessary to alleviate the anxiety of repeated fed-batch fermentation with seeds in the decline phase.

A sequential fed-batch fermentation, in which C. butyricum DL07 in exponential growth period was inoculated into a new fermentation in turn, was proposed in this study (Figure 1). As predicted, the experiments were carried out for eight cycles successfully without a significant decrease in concentration of 1,3-PDO. The concentrations of by-products (butyrate and acetate) also did not appear significant fluctuations. The trends of 1,3-PDO production and microbial growth were similar in eight separate fermentations. Especially during the first $10 \mathrm{~h}$ of production, it can be seen that the formation of 1,3-PDO was stable. For this reason, the strain cultured in bioreactor for $10 \mathrm{~h}$ was reliable to be inoculums. It is worth mentioning that only $2 \%$ fermentation broth was inoculated into the next cycle in sequential fed-batch fermentation. The inoculation was generally 5\%-10\% in most of the 1,3-PDO fermentations (Chatzifragkou et al.,2011,2014;Lee, Jung, \& Oh,2018; Yang et al.,2018). Compared with traditional fed-batch fermentation, the stable 1,3-PDO concentration was obtained in repeated fed-batch fermentation with $10 \%$ inoculation(Oh et al.,2018a;Xue et al.,2010). There is no doubt that $2 \%$ inoculation without negative effects on 1,3-PDO production will bring more benefits to enterprises. On the whole, in sequential fed-batch fermentation, the average concentration of 1,3-PDO in eight cycles was $84.62 \mathrm{~g} / \mathrm{L}$ with the average productivity of $3.05 \mathrm{~g} /\left(\mathrm{L}^{*} \mathrm{~h}\right)$. In this process, the time of seed cultivation in traditional fermentation was avoided, and the potential problem of fewer cycle times caused by poor seed quality in repeated batch and fed-batch fermentation was solved as well. Successfully, semi-continuous production of 1,3-PDO was achieved in this process. In a word, the sequential fed-batch fermentation is a stable process for 1,3-PDO production so as to be used for industrialization.

\section{The production of 1,3-PDO with an automatic glycerol feeding system}

Regrettably, the glycerol was manually pumped into the bioreactor in the sequential fed-batch fermentation. Generally, measuring glycerol concentration in time is required for two feeding strategies (continuous feeding and pulse feeding) in fed-batch fermentation. In continuous feeding, glycerol is manually fed into the bioreactor with a constant or varying rate to remain a certain range of concentration(Chen et al.,2003;Jiang et al.,2017). And in pulse feeding, whenever the glycerol concentration decreases to a preset value, the glycerol is manually added to the bioreactor to reach a specific concentration(Chatzifragkou et al.,2014;Hiremath, Kannabiran, \& Rangaswamy,2011;Zhou et al.,2017). This is undoubtedly a technical labor burden for industrial production and increases the instability of fermentation. There are some automatically feeding strategies for 1,3-propanediol fermentation by K. pneumoniae. For example, glycerol feeding is coupled with the consumption of alkali and fermentation time(Huang, Chen, Sun, \& Liu,2015). And coupling glycerol feeding with the alkali consumption and the production of carbon dioxide has been studied (Song, TENG, \& Xiu,2012). In another report, a method was developed of coupling glycerol feeding and ammonium with alkali consumption (Reimann \& Biebl,1996). These methods were applied based on two relations. However, 
these relationships do not apply to C. butyricum DL07, so a simple and easy-to-operate automatic feeding strategy is needed.

In sequential fed-batch fermentation, a large amount of data was collected and used to explore their relationship. Finally, a good linear relationship was established between the mass consumption of glycerol and 5M $\mathrm{NaOH}$ solution (Figure 6). The pumping times of $5 \mathrm{M} \mathrm{NaOH}$ were recorded by the bioreactor system. So the automatic glycerol feeding can be realized by coupling a computer with a bioreactor system. Of course, this linear relationship must be put into the computer. In this way, glycerol can remain a certain concentration during fermentation by the automatic feeding system. When the glycerol fed in bioreactor reaches a set value, the feed will be stopped so as to remain the glycerol concentration within a reasonable range at the end of fermentation. This set value is calculated based on the final 1,3-PDO concentration and conversion rate in fed-batch fermentation. After all, the residual glycerol concentration should be low enough to relieve the pressure of separating 1,3-PDO from glycerol (Xiu et al.,2004). To further verify the applicability of the linear relationship we obtained, fed-batch fermentation was subsequently performed. Obviously, when the initial glycerol concentration decreased to $20 \mathrm{~g} / \mathrm{L}$, the concentration of glycerol remained $18.44-21.66 \mathrm{~g} / \mathrm{L}$ by automatic glycerol feeding strategy. As predicted, when the fermentation was finished, the residual glycerol concentration in bioreactor was relatively lower $(5.97 \mathrm{~g} / \mathrm{L})$ and 1,3-PDO concentration, conversion rate and productivity maintained at the same level compared with manual glycerol feeding. This means that the automatic feeding system is well-suited for the fermentation of $C$. butyricum DL07. This automatic feeding system provides an operator-independent, repeatable and highly desirable process for 1,3-PDO production by $C$. butyricum DL07 fermentation from lab-scale to industrial scale. In the future, the novel sequential fed-batch fermentation with an automatic glycerol feeding system will have an opportunity to be used in industrial production of 1,3-PDO.

\section{CONCLUSION}

C. butyricum DL07 possess a certain robustness, and it can convert pure and crude glycerol to $1,3-\mathrm{PDO}$ by using two feeding strategies in fed-batch fermentation. And the concentration of 1,3-PDO was stable and higher than $80 \mathrm{~g} / \mathrm{L}$. When the feeding solution was a mixture of yeast and glycerol, to our surprise, 104.78 and $94.23 \mathrm{~g} / \mathrm{L}$ 1,3-PDO were obtained using pure and crude glycerol as substrate with an overall productivity of 3.38 and $3.04 \mathrm{~g} /\left(\mathrm{L}^{*} \mathrm{~h}\right)$, respectively. To our knowledge, these are among the best results published so far for natural producers. Then, corn steep liquor powder as an inexpensive alternative nitrogen source can be used for 1,3-PDO production to reduce the production cost. In addition, it is expected that fermentation exist gas and nitrogen are used as aerating gas in a suitable proportion so as to increase 1,3-PDO productivity without the loss of concentration and conversion rate. In this way, the cost of fermentation and pressure on environment caused by the exhaust will be reduced at the same time. More importantly, a sequential fed-batch fermentation process was established to achieve a stable, semi-continuous 1,3-PDO production. In this process, the average concentration of 1,3-PDO, $84.62 \mathrm{~g} / \mathrm{L}$, was obtained with the average productivity of $3.05 \mathrm{~g} /\left(\mathrm{L}^{*} \mathrm{~h}\right)$. This process avoids seed cultivation and solves the potential problem of fewer cycle times caused by poor seed quality in repeated fed-batch fermentation. Furthermore, an automatic glycerol feeding strategy was applied in the production of $1,3-\mathrm{PDO}$ by coupling the mass consumption of glycerol with $5 \mathrm{M}$ $\mathrm{NaOH}$ solution. Therefore, the novel sequential fed-batch fermentation with an automatic glycerol feeding system will have an opportunity to be used in the industrial production of 1,3-PDO. This sequential fed-batch fermentation with an automatic glycerol feeding system and optimization of fermentation may be valuable for reducing the cost of 1,3-PDO production and promote the industrial production of 1,3-propanediol by $C$. butyricum .

\section{Acknowledgements}

This work was supported by the National Natural Science Foundation of China (Grant 521 No. 21476042) and the Fundamental Research Funds for the Central Universities 522 (Grant No. DUT17ZD209)

\section{References:}


Anitha, M., Kamarudin, S. K., \& Kofli, N. T. (2016). The potential of glycerol as a value-added commodity. Chemical Engineering Journal , 295, 119-130. doi: https://doi.org/10.1016/j.cej.2016.03.012

Cassir, N., Benamar, S., \& La Scola, B. (2016). Clostridium butyricum : from beneficial to a new emerging pathogen. Clinical Microbiology and Infection , 22(1), 37-45. doi: https://doi.org/10.1016/j.cmi.2015.10.014

Chatzifragkou, A., Dietz, D., Komaitis, M., Zeng, A. P., \& Papanikolaou, S. (2010). Effect of biodieselderived waste glycerol impurities on biomass and 1,3-propanediol production of Clostridium butyricum VPI 1718.Biotechnology and bioengineering , 107(1), 76-84. doi: https://doi.org/10.1007/s00253-012-4111-3

Chatzifragkou, A., Papanikolaou, S., Dietz, D., Doulgeraki, A. I., Nychas, G. E.,... Zeng, A. (2011). Production of 1,3-propanediol by Clostridium butyricum growing on biodiesel-derived crude glycerol through a non-sterilized fermentation process. Applied Microbiology and Biotechnology , 91(1), 101-112. doi: $10.1007 / \mathrm{s} 00253-011-3247-\mathrm{x}$

Chatzifragkou, A., Papanikolaou, S., Kopsahelis, N., Kachrimanidou, V., Dorado, M. P.,... Koutinas, A. A. (2014). Biorefinery development through utilization of biodiesel industry by-products as sole fermentation feedstock for 1,3-propanediol production. Bioresource Technology , 159, 167-175. doi: https://doi.org/10.1016/j.biortech.2014.02.021

Chatzifragkou, A., \& Papanikolaou, S. (2012). Effect of impurities in biodiesel-derived waste glycerol on the performance and feasibility of biotechnological processes. Applied Microbiology and Biotechnology , 95(1), 13-27. doi: 10.1007/s00253-012-4111-3

Chen, X., Zhang, D., Qi, W., Gao, S., Xiu, Z.,... Xu, P. (2003). Microbial fed-batch production of 1,3propanediol by Klebsiella pneumoniaeunder micro-aerobic conditions. Applied Microbiology and Biotechnology , 63(2), 143-146. doi: https://doi.org/10.1007/s00253-003-1369-5

Colin, T., Bories, A., \& Moulin, G. (2000). Inhibition ofClostridium butyricum by 1,3-propanediol and diols during glycerol fermentation. Applied Microbiology and Biotechnology , 54(2), 201-205. doi: https://doi.org/10.1007/s002530000365

Guo, Y., Dai, L., Xin, B., Tao, F., Tang, H., Shen, Y.,... Xu, P. (2017). 1,3-Propanediol production by a newly isolated strain, Clostridium perfringens GYL. Bioresource Technology , 233, 406-412. doi: https://doi.org/10.1016/j.biortech.2017.02.116

Hakalehto, E., \& Hanninen, O. (2012). Gaseous $\mathrm{CO}_{2}$ signal initiates growth of butyric-acid-producing Clostridium butyricum in both pure culture and mixed cultures with Lactobacillus brevis. Canadian journal of microbiology , 58(7), 928-931. doi: https://doi.org/10.1139/w2012-059

Hiremath, A., Kannabiran, M., \& Rangaswamy, V. (2011). 1,3-Propanediol production from crude glycerol from jatropha biodiesel process. New Biotechnology , 28(1), 19-23. doi: https://doi.org/10.1016/j.nbt.2010.06.006

Hirschmann, S., Baganz, K., Koschik, I., \& Vorlop, K. D. (2005). Development of an integrated bioconversion process for the production of 1,3-propanediol from raw glycerol waters. Landbauforschung Volkenrode, 55(4), 261-267. doi: https://doi.org/10.1300/J064v25n03_09

Huang, J., Chen, Z., Sun, Y., \& Liu, D. (2015). Automatically feeding strategy for 1, 3-propanediol fermentation of Klebsiella pneumoniaeLDH526. Sheng wu gong cheng xue bao= Chinese journal of biotechnology , 31(10), 1520-1527

Ji, X., Huang, H., Zhu, J., Hu, N., \& Li, S. (2009). Efficient 1,3-propanediol production by fed-batch culture of Klebsiella Pneumoniae: The role of pH fluctuation. Applied Biochemistry and Biotechnology , 159(3), 605. doi: 10.1007/s12010-008-8492-9

Jiang, L., Liu, H., Mu, Y., Sun, Y., \& Xiu, Z. (2017). High tolerance to glycerol and high production of 1,3-propanediol in batch fermentations by microbial consortium from marine sludge. Engineering in Life 
Sciences , 17(6), 635-644. doi: 10.1002/elsc.201600215

Jiang, W., Wang, S., Wang, Y., \& Fang, B. (2016). Key enzymes catalyzing glycerol to 1,3-propanediol. Biotechnology for Biofuels , 9(1), 57. doi: 10.1186/s13068-016-0473-6

Jin, P., Lu, S., Huang, H., Luo, F., \& Li, S. (2011). Enhanced reducing equivalent generation for 1,3propanediol production through cofermentation of glycerol and xylose by Klebsiella pneumoniae. Applied Biochemistry and Biotechnology , 165(7), 1532-1542. doi: 10.1007/s12010-011-9373-1

Jolly, J., Hitzmann, B., Ramalingam, S., \& Ramachandran, K. B. (2014). Biosynthesis of 1,3-propanediol from glycerol with Lactobacillus reuteri : Effect of operating variables. Journal of Bioscience and Bioengineering , 118(2), 188-194. doi: https://doi.org/10.1016/j.jbiosc.2014.01.003

Ju, J., Wang, D., Heo, S., Kim, M., Seo, J., Kim, Y.,... Oh, B. (2020). Enhancement of 1,3-propanediol production from industrial by-product byLactobacillus reuteri CH53. Microbial Cell Factories , 19(1), 6. doi: $10.1186 / \mathrm{s} 12934-019-1275-\mathrm{x}$

Jun, S., Moon, C., Kang, C., Kong, S. W., Sang, B.,.. Um, Y. (2010). Microbial fed-batch production of 1,3-propanediol using raw glycerol with suspended and immobilized Klebsiella pneumoniae. Applied biochemistry and biotechnology , 161(1-8), 491-501. doi: https://doi.org/10.1007/s12010-009-8839-x

Kaur, G., Srivastava, A. K., \& Chand, S. (2012). Advances in biotechnological production of 1,3-propanediol. Biochemical Engineering Journal , 64, 106-118. doi: https://doi.org/10.1016/j.bej.2012.03.002

Kaur, G., Srivastava, A. K., \& Chand, S. (2012). Simple strategy of repeated batch cultivation for enhanced production of 1,3-propanediol using Clostridium diolis . Applied biochemistry and biotechnology , 167(5), 1061-1068. doi: https://doi.org/10.1007/s12010-012-9715-7

Lee, C. S., Aroua, M. K., Daud, W. M. A. W., Cognet, P., Peres-Lucchese, Y., Fabre, P.,... Latapie, L. (2015). A review: Conversion of bioglycerol into 1,3-propanediol via biological and chemical method. Renewable and Sustainable Energy Reviews , 42, 963-972. doi: https://doi.org/10.1016/j.rser.2014.10.033

Lee, J. H., Jung, M., \& Oh, M. (2018). High-yield production of 1,3-propanediol from glycerol by metabolically engineered Klebsiella pneumoniae . Biotechnology for Biofuels , 11(1), 104. doi: 10.1186/s13068-018$1100-5$

Liu, H., Xu, Y., Zheng, Z., \& Liu, D. (2010). 1,3-Propanediol and its copolymers: r research, development and industrialization. Biotechnology Journal , 5(11), 1137-1148. doi: 10.1002/biot.201000140

Maina, S., Kachrimanidou, V., Ladakis, D., Papanikolaou, S., de Castro, A. M.,... Koutinas, A. (2019). Evaluation of 1,3-propanediol production by two Citrobacter freundii strains using crude glycerol and soybean cake hydrolysate. Environmental Science and Pollution Research , 26(35), 35523-35532. doi: https://doi.org/10.1007/s11356-019-05485-4

Matsumura, M., Nomura, N., \& Sato, S. (2008). Growth and 1,3-propanediol production on pre-treated sunflower oil bio-diesel raw glycerol using a strict anaerobe-Clostridium butyricum . Current Research in Bacteriology , 1(1), 7-16. doi: https://doi.org/10.3923/crb.2008.7.16

Metsoviti, M., Zeng, A., Koutinas, A. A., \& Papanikolaou, S. (2013). Enhanced 1,3-propanediol production by a newly isolatedCitrobacter freundii strain cultivated on biodiesel-derived waste glycerol through sterile and non-sterile bioprocesses. Journal of Biotechnology , 163(4), 408-418. doi: https://doi.org/10.1016/j.jbiotec.2012.11.018

Mu, Y., Teng, H., Zhang, D., Wang, W., \& Xiu, Z. (2006). Microbial production of 1,3-propanediol by Klebsiella pneumoniae using crude glycerol from biodiesel preparations. Biotechnology Letters , 28(21), 1755-1759. doi: 10.1007/s10529-006-9154-z

Oh, B., Lee, S., Heo, S., Seo, J., \& Kim, C. H. (2018a). Efficient production of 1,3-propanediol from crude glycerol by repeated fed-batch fermentation strategy of a lactate and 2,3-butanediol deficient mutant of 
Klebsiella pneumoniae. Microbial Cell Factories , 17(1), 92. doi: 10.1186/s12934-018-0921-z

Parate, R., Mane, R., Dharne, M., \& Rode, C. (2018). Mixed bacterial culture mediated direct conversion of bio-glycerol to diols. Bioresource Technology , 250, 86-93. doi: https://doi.org/10.1016/j.biortech.2017.11.019

Pflugl, S., Marx, H., Mattanovich, D., \& Sauer, M. (2014). Heading for an economic industrial upgrading of crude glycerol from biodiesel production to 1,3-propanediol by Lactobacillus diolivorans . Bioresource Technology , 152, 499-504. doi: https://doi.org/10.1016/j.biortech.2013.11.041

Rahim, S. A. N. M., Lee, C. S., Abnisa, F., Aroua, M. K., Daud, W. A. W., Cognet, P.,... Peres, Y. (2020). A review of recent developments on kinetics parameters for glycerol electrochemical conversion - A by-product of biodiesel. Science of The Total Environment , 705, 135137. doi: https://doi.org/10.1016/j.scitotenv.2019.135137

Reimann, A., \& Biebl, H. (1996). Production of 1,3-propanediol by Clostridium butyricum DSM 5431 and product tolerant mutants in fedbatch culture: Feeding strategy for glycerol and ammonium.Biotechnology Letters , 18(7), 827-832. doi: https://doi.org/10.1007/BF00127897

Ringel, A. K., Wilkens, E., Hortig, D., Willke, T., \& Vorlop, K. (2012). An improved screening method for microorganisms able to convert crude glycerol to 1,3-propanediol and to tolerate high product concentrations. Applied Microbiology and Biotechnology , 93(3), 1049-1056. doi: https://doi.org/10.1007/s00253-011-3594-7

Saint-Amans, S., Girbal, L., Andrade, J., Ahrens, K., \& Soucaille, P. (2001). Regulation of carbon and electron flow in Clostridium butyricumVPI 3266 grown on glucose-glycerol mixtures. Journal of Bacteriology , 183(5), 1748-1754. doi: https://doi.org/10.1128/JB.183.5.1748-1754.2001

Saxena, R. K., Anand, P., Saran, S., \& Isar, J. (2009). Microbial production of 1,3-propanediol: Recent developments and emerging opportunities.Biotechnology Advances , 27(6), 895-913. doi: https://doi.org/10.1016/j.biotechadv.2009.07.003

Sharma, P., \& Melkania, U. (2018). Enhancement effect of amino acids on hydrogen production from organic fraction of municipal solid waste using co-culture of Escherichia coli and Enterobacter aerogenes .Energy Conversion and Management , 163, 260-267. doi: https://doi.org/10.1016/j.enconman.2018.02.072

Song, Z. Y., TENG, H., \& Xiu, Z. L. (2012). Coupled-feeding strategy based on the cell growth and metabolism during 1,3-propanediol fermentation. The Chinese Journal of Process Engineering , 12(6), 9961001

Sun, Y., Shen, J., Yan, L., Zhou, J., Jiang, L., Chen, Y.,.. Xiu, Z. (2018). Advances in bioconversion of glycerol to 1,3-propanediol: Prospects and challenges. Process Biochemistry , 71, 134-146. doi: https://doi.org/10.1016/j.procbio.2018.05.009

Szymanowska-Powalowska, D. (2014). 1,3-Propanediol production from crude glycerol by Clostridium butyricum DSP1 in repeated batch. Electronic Journal of Biotechnology , 17(6), 322-328. doi: http://dx.doi.org/10.1016/j.ejbt.2014.10.00

Tee, Z. K., Jahim, J. M., Tan, J. P., \& Kim, B. H. (2017). Preeminent productivity of 1,3-propanediol by Clostridium butyricum JKT37 and the role of using calcium carbonate as $\mathrm{pH}$ neutraliser in glycerol fermentation. Bioresource Technology , 233, 296-304. doi: https://doi.org/10.1016/j.biortech.2017.02.110

Vivek, N., Pandey, A., \& Binod, P. (2017). 31 - Production and Applications of 1,3-Propanediol. In A. Pandey, S. Negi \& C. R. Soccol (Eds.), Current Developments in Biotechnology and Bioengineering(719-738): Elsevier. doi: https://doi.org/10.1016/B978-0-444-63662-1.00031-2

Westbrook, A. W., Miscevic, D., Kilpatrick, S., Bruder, M. R., Moo-Young, M.,... Chou, C. P. (2019). Strain engineering for microbial production of value-added chemicals and fuels from glycerol. Biotechnology Advances , 37(4), 538-568. doi: https://doi.org/10.1016/j.biotechadv.2018.10.006 
Wilkens, E., Ringel, A. K., Hortig, D., Willke, T., \& Vorlop, K. (2012). High-level production of 1,3propanediol from crude glycerol by Clostridium butyricum AKR102a. Applied Microbiology and Biotechnology , 93(3), 1057-1063. doi: 10.1007/s00253-011-3595-6

Wischral, D., Zhang, J., Cheng, C., Lin, M., De Souza, L. M. G., Pessoa, F. L. P.,... Yang, S. (2016). Production of 1,3-propanediol byClostridium beijerinckii DSM 791 from crude glycerol and corn steep liquor: Process optimization and metabolic engineering.Bioresource Technology , 212, 100-110. doi: https://doi.org/10.1016/j.biortech.2016.04.020

Xiu, Z., Song, B., Wang, Z., Sun, L., Feng, E.,... Zeng, A. (2004). Optimization of dissimilation of glycerol to 1,3-propanediol byKlebsiella pneumoniae in one- and two-stage anaerobic cultures.Biochemical Engineering Journal , 19(3), 189-197. doi: https://doi.org/10.1016/j.bej.2003.12.005

Xiu, Z., Wang, X., Zhou, J., \& Sun, Y. (2019). Bioconversion of raw glycerol from waste cooking-oil-based biodiesel production to 1,3-propanediol and lactate by a microbial consortium. Frontiers in bioengineering and biotechnology , 7, 14. doi: https://doi.org/10.3389/fbioe.2019.00014

Xiu, Z., \& Zeng, A. (2008). Present state and perspective of downstream processing of biologically produced 1,3-propanediol and 2,3-butanediol.Applied Microbiology and Biotechnology , 78(6), 917-926. doi: $10.1007 / \mathrm{s} 00253-008-1387-4$

Xue, X., Li, W., Li, Z., Xia, Y., \& Ye, Q. (2010). Enhanced 1,3-propanediol production by supply of organic acids and repeated fed-batch culture.Journal of Industrial Microbiology $\&$ Biotechnology , 37(7), 681-687. doi: 10.1007/s10295-010-0711-z

Yang, F., Hanna, M. A., \& Sun, R. (2012). Value-added uses for crude glycerol-a byproduct of biodiesel production. Biotechnology for Biofuels , 5(1), 13. doi: 10.1186/1754-6834-5-13

Yang, M., An, Y., Zabed, H. M., Guo, Q., Yun, J., Zhang, G.,... Qi, X. (2019). Random mutagenesis of Clostridium butyricum strain and optimization of biosynthesis process for enhanced production of 1,3propanediol. Bioresource Technology , 284, 188-196. doi: https://doi.org/10.1016/j.biortech.2019.03.098

Yang, X., Choi, H. S., Lee, J. H., Lee, S. K., Han, S. O., Park, C.,... Kim, S. W. (2018). Improved production of 1,3-propanediol from biodiesel-derived crude glycerol by Klebsiella pneumoniae in fed-batch fermentation. Chemical Engineering Journal , 349, 25-36. doi: https://doi.org/10.1016/j.cej.2018.05.042

Yang, X., Kim, D. S., Choi, H. S., Kim, C. K., Thapa, L. P., Park, C.,... Kim, S. W. (2017). Repeated batch production of 1,3-propanediol from biodiesel derived waste glycerol by Klebsiella pneumoniae .Chemical Engineering Journal , 314, 660-669. doi: https://doi.org/10.1016/j.cej.2016.12.029

Zeng, A., \& Sabra, W. (2011). Microbial production of diols as platform chemicals: recent progresses. Current Opinion in Biotechnology , 22(6), 749-757. doi: https://doi.org/10.1016/j.copbio.2011.05.005

Zhang, A. H., Liu, H. L., Huang, S. Y., Fu, Y. S., \& Fang, B. S. (2018). Metabolic profiles analysis of 1,3-propanediol production process byClostridium butyricum through repeated batch fermentation coupled with activated carbon adsorption. Biotechnology and bioengineering , 115(3), 684-693. doi: https://doi.org/10.1002/bit.26488

Zhou, J., Shen, J., Jiang, L., Sun, Y., Mu, Y.,.. Xiu, Z. (2017). Selection and characterization of an anaerobic microbial consortium with high adaptation to crude glycerol for 1,3-propanediol production. Applied Microbiology and Biotechnology , 101(15), 5985-5996. doi: 10.1007/s00253-017-8311-8

Zhou, J., Shen, J., Wang, X., Sun, Y., \& Xiu, Z. (2018). Stability and oscillatory behavior of microbial consortium in continuous conversion of crude glycerol to 1,3-propanediol. Applied Microbiology and Biotechnology , 102(19), 8291-8305. doi: 10.1007/s00253-018-9244-6

TABLE 1 Sequential fed-batch fermentations by C. butyricum DL07 


\begin{tabular}{|c|c|c|c|c|c|c|}
\hline $\begin{array}{l}\text { Sequential } \\
\text { fermentations }\end{array}$ & 1,3-PDO $(\mathrm{g} / \mathrm{L})$ & Butyrate $(\mathrm{g} / \mathrm{L})$ & Acetate $(\mathrm{g} / \mathrm{L})$ & Lactate $(\mathrm{g} / \mathrm{L})$ & $\begin{array}{l}\mathrm{Q}_{1,3-\mathrm{PDO}}(\mathrm{g} \\
\left.\mathrm{L}^{-1} \mathrm{~h}^{-1}\right)\end{array}$ & $\begin{array}{l}\text { Conversion } \\
\text { rate (g } 1,3-\mathrm{PDO} \\
\left./ \mathrm{g}_{\mathrm{Gly}}\right)\end{array}$ \\
\hline $\begin{array}{l}\text { Seed culture } \\
\text { I }\end{array}$ & 6.30 & 0.99 & 0.72 & 1.01 & - & - \\
\hline $\begin{array}{l}\text { Seed culture } \\
\text { II }\end{array}$ & 6.98 & 0.74 & 1.15 & 0.98 & - & - \\
\hline $\begin{array}{l}\text { Seed culture } \\
\text { III }\end{array}$ & 14.69 & 1.88 & 2.08 & 1.46 & - & - \\
\hline $\begin{array}{l}\text { Fermentation } \\
\text { I }\end{array}$ & 84.04 & 17.53 & 6.59 & 2.91 & 2.80 & 0.52 \\
\hline $\begin{array}{l}\text { Fermentation } \\
\text { II }\end{array}$ & 88.59 & 17.50 & 7.80 & 3.59 & 3.54 & 0.54 \\
\hline $\begin{array}{l}\text { Fermentation } \\
\text { III }\end{array}$ & 82.20 & 16.39 & 7.76 & 4.12 & 2.74 & 0.50 \\
\hline $\begin{array}{l}\text { Fermentation } \\
\text { IV }\end{array}$ & 86.30 & 17.31 & 3.98 & 3.02 & 2.88 & 0.53 \\
\hline $\begin{array}{l}\text { Fermentation } \\
\mathrm{V}\end{array}$ & 88.18 & 17.24 & 8.29 & 4.32 & 3.83 & 0.54 \\
\hline $\begin{array}{l}\text { Fermentation } \\
\text { VI }\end{array}$ & 82.31 & 16.35 & 7.79 & 4.18 & 2.84 & 0.50 \\
\hline $\begin{array}{l}\text { Fermentation } \\
\text { VII }\end{array}$ & 84.65 & 16.53 & 8.03 & 2.54 & 3.02 & 0.52 \\
\hline $\begin{array}{l}\text { Fermentation } \\
\text { VIII }\end{array}$ & 80.65 & 15.22 & 7.96 & 2.19 & 2.78 & 0.49 \\
\hline Average & $84.62 \pm 2.89$ & $16.76 \pm 0.79$ & $7.28 \pm 1.42$ & $3.36 \pm 0.81$ & $3.05 \pm 0.41$ & $0.52 \pm 0.02$ \\
\hline
\end{tabular}

TABLE 2 Summary of high-level 1,3-PDO production from natural producers in fed-batch fermentations

\begin{tabular}{|c|c|c|c|c|c|c|c|c|c|c|}
\hline Microorg & $\begin{array}{l}\text { Titer } \\
\text { níggL }^{-1} \text { ) }\end{array}$ & $\begin{array}{l}\text { Yield } \\
\left(\text { g. } \mathrm{g}^{-1}\right)\end{array}$ & $\begin{array}{l}\text { Yield } \\
\left(\text { g. } \mathrm{g}^{-1}\right)\end{array}$ & $\begin{array}{l}\text { Yield } \\
\left(\text { g. } \mathrm{g}^{-1}\right)\end{array}$ & $\begin{array}{l}\text { Yield } \\
\left(\text { g. } \mathrm{g}^{-1}\right)\end{array}$ & $\begin{array}{l}\text { Overall } \\
\text { produc- } \\
\text { tivity } \\
(\text { g.L } \\
\left.{ }^{-1} \cdot \mathrm{h}^{-1}\right)\end{array}$ & $\begin{array}{l}\text { Glycerol } \\
\text { source }\end{array}$ & $\begin{array}{l}\text { Glycerol } \\
\text { source }\end{array}$ & $\begin{array}{l}\text { Glycerol } \\
\text { source }\end{array}$ & Ref. \\
\hline $\begin{array}{l}\text { C. bu- } \\
\text { tyricum } \\
\text { IK } \\
124\end{array}$ & 87.7 & 87.7 & 0.54 & 0.54 & 1.90 & 1.90 & 1.90 & Refined & \multicolumn{2}{|c|}{$\begin{array}{l}\text { (Hirschman(Hirschma } \\
\text { Baganz, Baganz, } \\
\text { Koschik, Koschik, } \\
\& \quad \& \\
\text { Vorlop,2005Vorlop,200 }\end{array}$} \\
\hline & 80.1 & 80.1 & 0.56 & 0.56 & 1.80 & 1.80 & 1.80 & Crude & & \\
\hline \multirow[t]{2}{*}{$\begin{array}{l}\text { C. bu- } \\
\text { tyricum } \\
\text { AKR } \\
102 \mathrm{a}\end{array}$} & 93.7 & 93.7 & 0.52 & 0.52 & 3.30 & 3.30 & 3.30 & Refined & $\begin{array}{l}\text { (Wilkens } \\
\text { et } \\
\text { al.,2012) }\end{array}$ & $\begin{array}{l}\text { (Wilkens } \\
\text { et } \\
\text { al.,2012) }\end{array}$ \\
\hline & 76.2 & 76.2 & 0.51 & 0.51 & 2.30 & 2.30 & 2.30 & Crude & & \\
\hline $\begin{array}{l}\text { C. bu- } \\
\text { tyricum } \\
\text { DSM } \\
5431\end{array}$ & 70.3 & 70.3 & 0.68 & 0.68 & 1.50 & 1.50 & 1.50 & Crude & \multicolumn{2}{|c|}{ 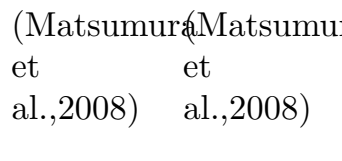 } \\
\hline
\end{tabular}




\begin{tabular}{|c|c|c|c|c|c|c|c|c|c|c|}
\hline Microorga & $\begin{array}{c}\text { Titer } \\
\left.\text { n(son- }{ }^{-1}\right)\end{array}$ & $\begin{array}{l}\text { Yield } \\
\left(\mathrm{g} \cdot \mathrm{g}^{-1}\right)\end{array}$ & $\begin{array}{l}\text { Yield } \\
\left(\mathrm{g} \cdot \mathrm{g}^{-1}\right)\end{array}$ & $\begin{array}{l}\text { Yield } \\
\left(\mathrm{g} \cdot \mathrm{g}^{-1}\right)\end{array}$ & $\begin{array}{l}\text { Yield } \\
\left(\mathrm{g} \cdot \mathrm{g}^{-1}\right)\end{array}$ & $\begin{array}{l}\text { Overall } \\
\text { produc- } \\
\text { tivity } \\
(\text { g.L } \\
\left.{ }^{-1} \cdot \mathrm{h}^{-1}\right)\end{array}$ & $\begin{array}{l}\text { Glycerol } \\
\text { source }\end{array}$ & $\begin{array}{l}\text { Glycerol } \\
\text { source }\end{array}$ & $\begin{array}{l}\text { Glycerol } \\
\text { source }\end{array}$ & Ref. \\
\hline $\begin{array}{l}\text { C. bu- } \\
\text { tyricum } \\
\text { VPI } \\
1718\end{array}$ & 67.9 & 67.9 & 0.55 & 0.55 & 0.78 & 0.78 & 0.78 & Crude & $\begin{array}{l}\text { (Chatzifra } \\
\text { et } \\
\text { al.,2011) }\end{array}$ & $\begin{array}{l}\text { gkGinatzifras } \\
\text { et } \\
\text { al.,2011) }\end{array}$ \\
\hline $\begin{array}{l}\text { K. } \\
\text { pneu- } \\
\text { mo- } \\
\text { niae } \\
\text { DSM } \\
4799\end{array}$ & 80.2 & 80.2 & 80.2 & 0.45 & 1.16 & 1.16 & 1.16 & Crude & $\begin{array}{l}\text { (Jun } \\
\text { et } \\
\text { al.,2010) }\end{array}$ & $\begin{array}{l}\text { (Jun } \\
\text { et } \\
\text { al.,2010) }\end{array}$ \\
\hline $\begin{array}{l}\text { K. } \\
\text { pneu- } \\
\text { mo- } \\
\text { niae } \\
\text { LX3 }\end{array}$ & 71.38 & 71.38 & 71.38 & 0.49 & 2.24 & 2.24 & 2.24 & Refined & $\begin{array}{l}\text { (Xue } \\
\text { et } \\
\text { al.,2010) }\end{array}$ & $\begin{array}{l}\text { (Xue } \\
\text { et } \\
\text { al.,2010) }\end{array}$ \\
\hline $\begin{array}{l}\text { K. } \\
\text { pneu- } \\
\text { mo- } \\
\text { niae } \\
\text { ME- } \\
303\end{array}$ & 67.21 & 67.21 & 67.21 & 0.52 & 1.82 & 1.82 & 1.82 & Refined & $\begin{array}{l}\text { (Jin, } \\
\text { Lu, } \\
\text { Huang, } \\
\text { Luo, } \\
\& \\
\text { Li,2011) }\end{array}$ & $\begin{array}{l}\text { (Jin, } \\
\text { Lu, } \\
\text { Huang, } \\
\text { Luo, } \\
\& \\
\text { Li,2011) }\end{array}$ \\
\hline $\begin{array}{l}\text { K. } \\
\text { pneu- } \\
\text { mo- } \\
\text { niae } \\
\text { ME- } \\
308\end{array}$ & 70 & 70 & 70 & 0.58 & 0.97 & 0.97 & 0.97 & Refined & $\begin{array}{l}\text { (Ji, } \\
\text { Huang, } \\
\text { Zhu, } \\
\mathrm{Hu}, \text { \& } \\
\mathrm{Li}, 2009)\end{array}$ & $\begin{array}{l}\text { (Ji, } \\
\text { Huang, } \\
\text { Zhu, } \\
\text { Hu, \& } \\
\text { Li,2009) }\end{array}$ \\
\hline $\begin{array}{l}K . \\
\text { pneu- } \\
\text { mo- } \\
\text { niae } \\
\text { DSM2026 }\end{array}$ & 61.9 & 61.9 & 61.9 & 0.4 & 2.0 & 2.0 & 2.0 & Refined & $\begin{array}{l}\text { (Mu, } \\
\text { Teng, } \\
\text { Zhang, } \\
\text { Wang, } \\
\text { \& } \\
\text { Xiu,2006) }\end{array}$ & $\begin{array}{l}\text { (Mu, } \\
\text { Teng, } \\
\text { Zhang, } \\
\text { Wang, } \\
\& \\
\text { Xiu,2006) }\end{array}$ \\
\hline $\begin{array}{l}C . \\
\text { fre- } \\
\text { undii } \\
\text { FMCC- } \\
\text { B294 }\end{array}$ & 68.1 & 68.1 & 68.1 & 0.40 & 0.79 & 0.79 & 0.79 & Crude & $\begin{array}{l}\text { (Metsoviti } \\
\text { Zeng, } \\
\text { Kouti- } \\
\text { nas, \& } \\
\text { Papanikol. }\end{array}$ & $\begin{array}{l}\text { (Metsoviti } \\
\text { Zeng, } \\
\text { Kouti- } \\
\text { nas, \& } \\
\text { ada,B日n3lłola }\end{array}$ \\
\hline $\begin{array}{l}L . d i- \\
\text { olivo- } \\
\text { rans } \\
\text { DSM } \\
14421\end{array}$ & 85.4 & 85.4 & 85.4 & 0.46 & 0.46 & 0.46 & 0.46 & Refined & $\begin{array}{l}\text { (Pflügl, } \\
\text { Marx, } \\
\text { Mat- } \\
\text { tano- } \\
\text { vich, } \\
\& \\
\text { Sauer,2014 }\end{array}$ & $\begin{array}{l}\text { (Pflügl, } \\
\text { Marx, } \\
\text { Mat- } \\
\text { tano- } \\
\text { vich, } \\
\& \\
\text { Sauer,2014 }\end{array}$ \\
\hline
\end{tabular}




\begin{tabular}{|c|c|c|c|c|c|c|c|c|c|c|}
\hline Microorgar & $\begin{array}{l}\text { Titer } \\
\left.\text { n(sog }{ }^{-1}\right)\end{array}$ & $\begin{array}{l}\text { Yield } \\
\left(\mathrm{g} \cdot \mathrm{g}^{-1}\right)\end{array}$ & $\begin{array}{l}\text { Yield } \\
\left(\text { g. } \mathrm{g}^{-1}\right)\end{array}$ & $\begin{array}{l}\text { Yield } \\
\left(\text { g. g }{ }^{-1}\right)\end{array}$ & $\begin{array}{l}\text { Yield } \\
\left(\mathrm{g} \cdot \mathrm{g}^{-1}\right)\end{array}$ & $\begin{array}{l}\text { Overall } \\
\text { produc- } \\
\text { tivity } \\
(\mathrm{g} . \mathrm{L} \\
\left.{ }^{-1} \cdot \mathrm{h}^{-1}\right)\end{array}$ & $\begin{array}{l}\text { Glycerol } \\
\text { source }\end{array}$ & $\begin{array}{l}\text { Glycerol } \\
\text { source }\end{array}$ & $\begin{array}{l}\text { Glycerol } \\
\text { source }\end{array}$ & Ref. \\
\hline $\begin{array}{l}. \\
\text { reuteri } \\
\text { ATCC } \\
55730\end{array}$ & 65.3 & 65.3 & 65.3 & 0.16 & 1.20 & 1.20 & 1.20 & Refined & $\begin{array}{l}\text { (Jolly, } \\
\text { Hitz- } \\
\text { mann, } \\
\text { Ra- } \\
\text { ma- } \\
\text { lingam, } \\
\text { \& } \\
\text { Ramachan }\end{array}$ & $\begin{array}{l}\text { (Jolly, } \\
\text { Hitz- } \\
\text { mann, } \\
\text { Ra- } \\
\text { ma- } \\
\text { lingam, } \\
\text { \& } \\
\text { dRammahdin }\end{array}$ \\
\hline \multirow[t]{2}{*}{$\begin{array}{l}\text { butyricum } \\
\text { DL07 }\end{array}$} & 104.8 & 104.8 & 104.8 & 0.54 & 3.38 & 3.38 & 3.38 & Refined & \multirow[t]{2}{*}{$\begin{array}{l}\text { This } \\
\text { study }\end{array}$} & \multirow[t]{2}{*}{$\begin{array}{l}\text { This } \\
\text { study }\end{array}$} \\
\hline & 94.2 & 94.2 & 94.2 & 0.52 & 3.04 & 3.04 & 3.04 & Crude & & \\
\hline
\end{tabular}

\section{Figures Legends}

FIGURE 1 The schematic process of sequential fed-batch fermentation

FIGURE 2 Fed-batch fermentation of 1,3-propanediol by C. butyricum DL07 using pure glycerol (A, C)and crude glycerol (C, D). Two feeding strategies were adopted including continuous feeding (A, B) and pulsed feeding $(\mathrm{C}, \mathrm{D})$. Values are means of two independent fermentations

FIGURE 3 Fed-batch fermentation by C. butyricum DL07 feeding a mixture of yeast and pure glycerol (A) or crude glycerol (B)

FIGURE 4 Fed-batch fermentation using corn steep liquor powder instead of yeast extract as organic nitrogen resource

FIGURE 5 Fed-batch fermentation by $C$. butyricum DL07 with different aerating gas supplies for $1 \mathrm{~h}$ before and after inoculation, respectively

FIGURE 6 The relationship between consumption of $5 \mathrm{M} \mathrm{NaOH}$ and glycerol

FIGURE 7 Fed-batch fermentation feeding automatically pure glycerol according to the linear relationship obtained in Figure 6 

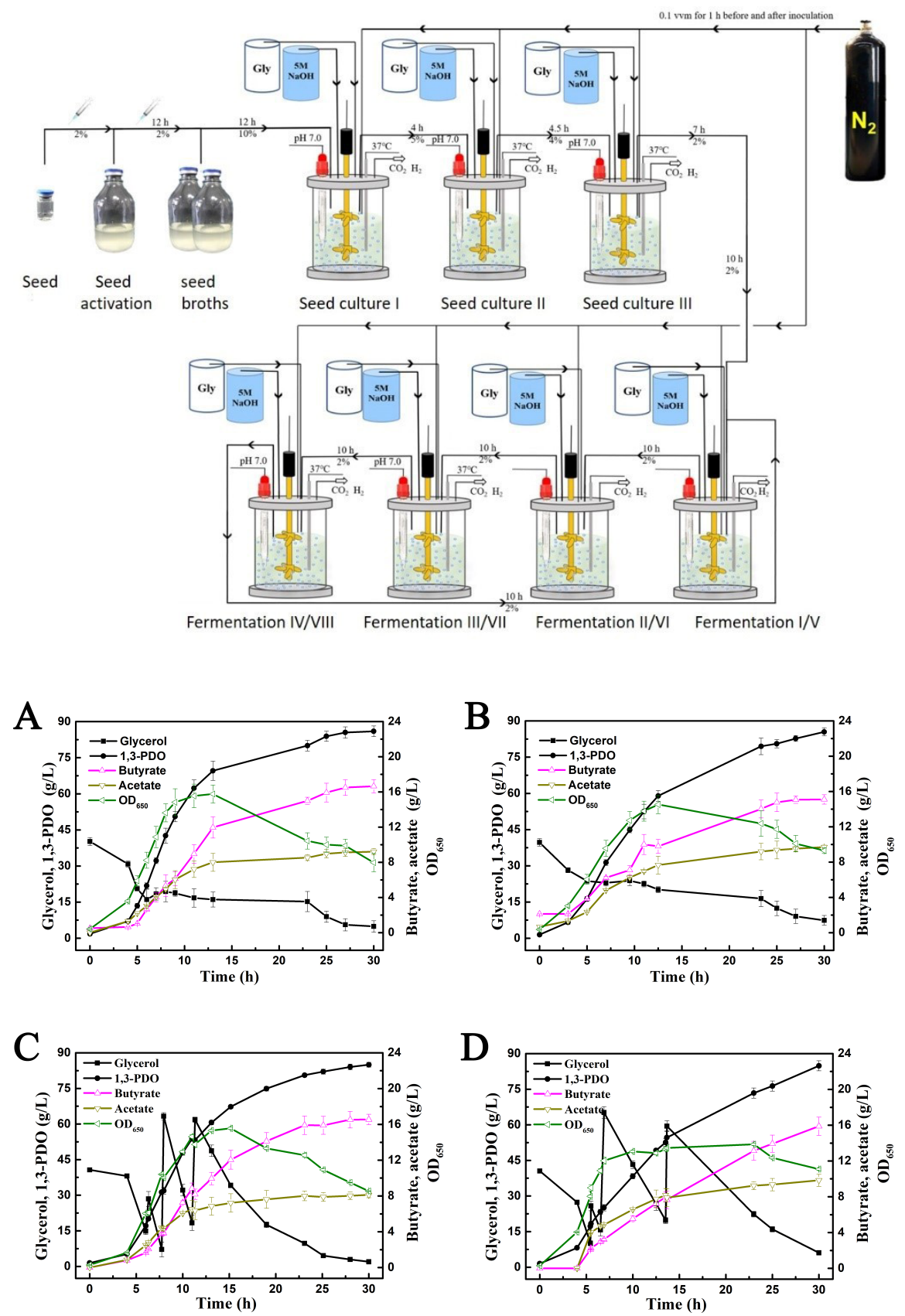

A

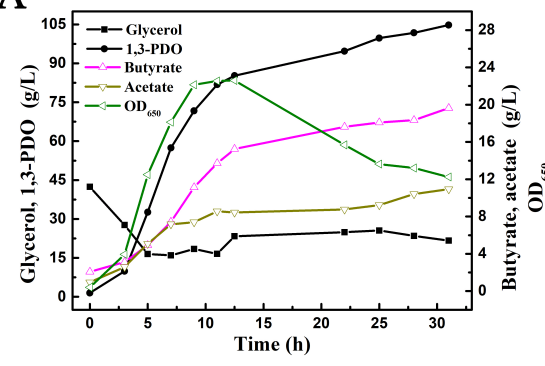

B

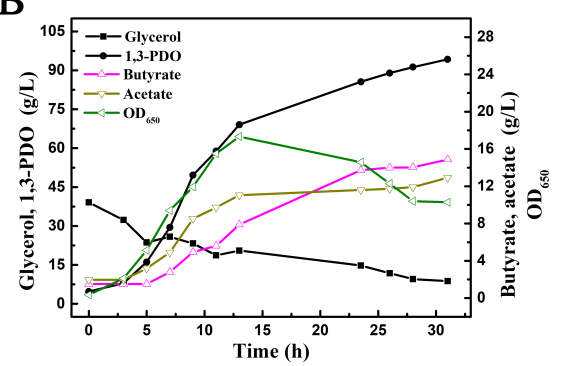



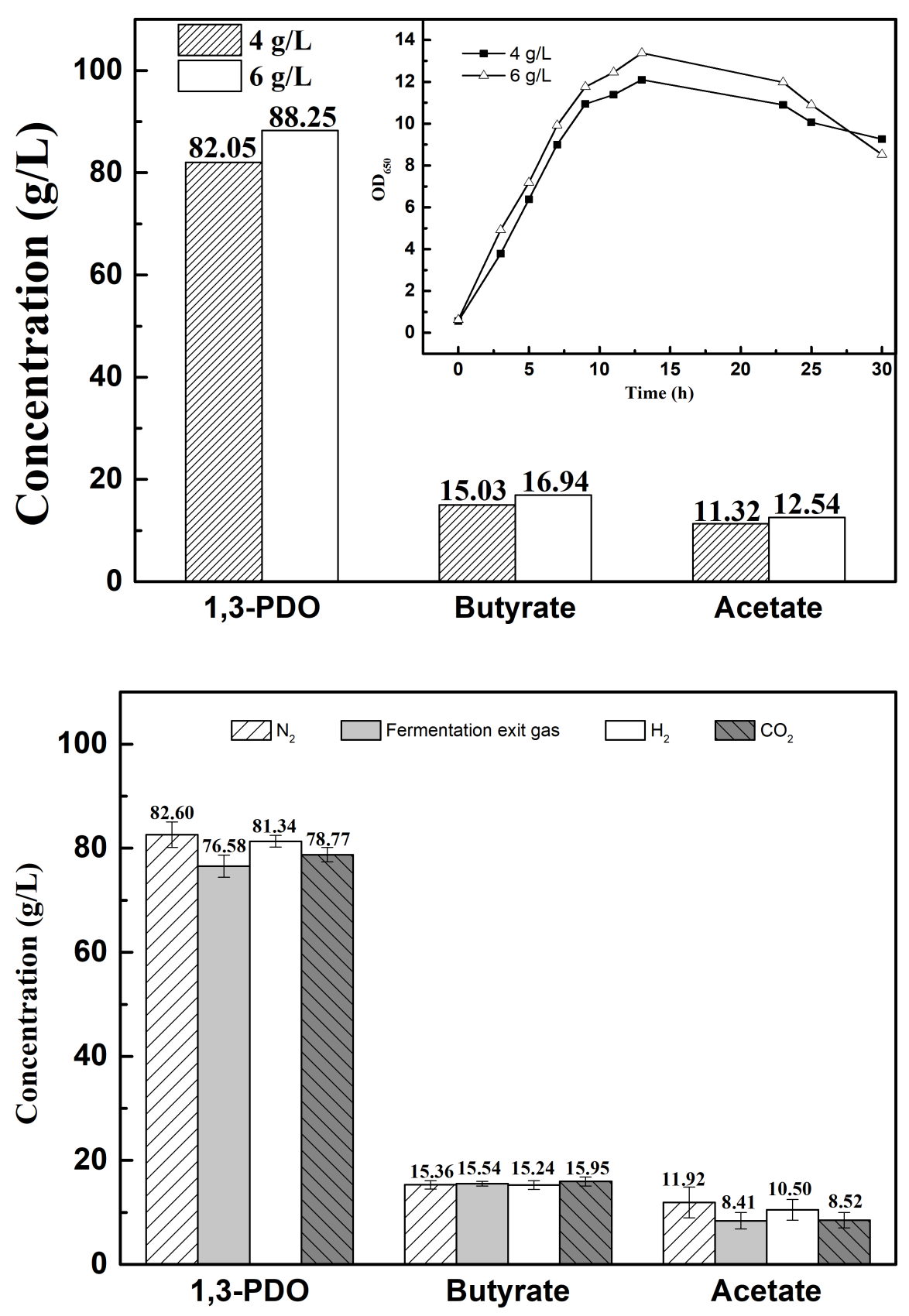

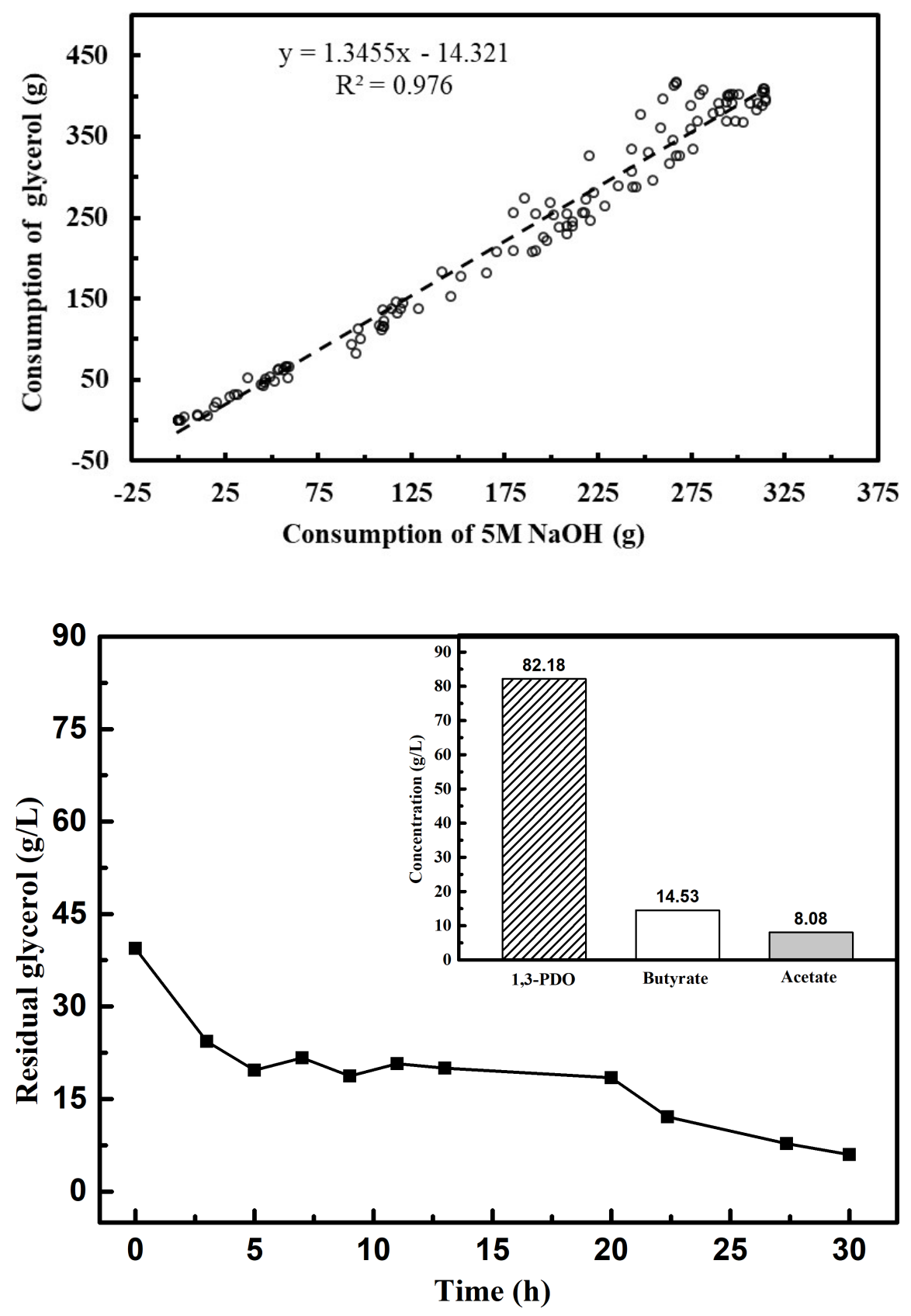